\title{
The Group Decision Support Model to Determine The Level of Depression Among Married Couple
}

\author{
Aridhanyati Arifin ${ }^{1}$, Yogi Cahya Gemilang ${ }^{2}$, Sri Kusumadewi ${ }^{3}$, Hepi Wahyuningsih ${ }^{4}$ \\ \{aridhanyati@uii.ac.id ${ }^{1}$, 13523207@ @tudents.uii.ac.id ${ }^{2}$, cicie@uii.ac.id ${ }^{3}$, hepi@fpsi.uii.ac.id ${ }^{4}$ \} \\ Universitas Islam Indonesia ${ }^{1234}$ \\ Yogyakarta, Indonesia
}

\begin{abstract}
According to the basic health research report in 2013, the Indonesian population has a mental disorder prevalence of up to 6 percent. The one of mental disorder is depression. Subject on this paper, focus on depression in marriage life. Recognizing depression is important. A psychologist usually performs a psychological assessment to achieve the prognosis and decide what strategies or approaches. Some case of depression involved by more than one psychologist. Therefore, to accommodate this condition, every psychologist can provide his preferences on criterion. Beck Depression Inventory (BDI) is the psychological assessment that usually used, but the BDI manual has determined one weight for all criteria, does not support group assessment. Hence, this paper proposes a new model which is combining BDI with another model resolve that issues. It is a group decision support model who combines BDI with Analytical Hierarchy Process (AHP) and Geometric Mean. The model provides an opportunity for the group of a psychologist to give their preferences with a minimal element of subjectivity. A group decision support model has been produced to determine the level of depression among married couples. Based on testing to expert, the proposed model is quite valid.
\end{abstract}

Keywords: AHP, BDI, Geometric Mean, Depression, Married Couple

\section{Introduction}

Statistical data from WHO stated that 300 million people are depressed, 60 million are bipolar, schizophrenia affecting 23 million people and 50 million people estimated as dementia[1]. According to the basic health research report in 2013, the Indonesian population has a mental disorder prevalence of up to 6 percent and the prevalence of mental disorders weighing around 1.7 per mile [2]. The one of mental disorder is depression. The depression is a mood disorder with several features such as sadness, pessimism, decrease activity, fatigue, weight loss, sleeplessness or sleep too much and feel inappropriate guilt [3]. Severe depression can encourage sufferers to commit suicide [3].

Depression condition has an impact on daily life including family life and relationships among married couples [4]. On the other hand, family conditions or marriage life can be one of the triggers of depression[5]. Subject on this paper, focus on depression in marriage life.

Recognizing depression is important. This activity requires handling from psychologists. A psychologist usually performs a psychological assessment to achieve the prognosis and decide what strategies or approaches are appropriate for treatment [6]. An assessment needs an appropriate measuring scale. Some case of depression involved by more than one psychologist. Therefore, to accommodate this condition, every psychologist can provide his preferences on criterion that used. Actually, these preferences can create strong subjectivity and also create a gap preference among psychologist. This will affect validity prognosis and therapy to be given. 
This case require a model which has capability to decrease subjectivity's issues. Beck Depression Inventory (BDI) is the psychological assessment that mostly used [7], but the BDI manual has determined one weight for all criteria, does not support group assessment. Hence, this paper proposes a new model which is combining BDI with several methods to resolve that issues. This is a group decision support model. Next, in implementation phase, the models will be running on computer system through the creation of a Group Decision Support System.

This paper will describe modeling of group decision support to determine level of depression among married couple.

\section{Research method}

There are several phases of research used to model a group decision support for determine level of depression among married couples. Figure 1 show the phases of this research.
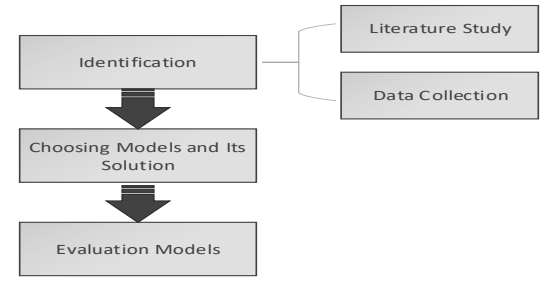

Fig 1. The Phases of Research

\subsection{Identification}

The first phase, doing identification in some literature that relate to this topic, such as some method which is used. The data takes from PUSKAGA UII, the institution which concern to family and marriage life.

The data such as the interpretation of BDI scores (shown in Table 2) and the item question of questionnaire.

Table 2. The Interpretation of BDI Score

\begin{tabular}{cc}
\hline Index & Level of Depression \\
\hline$<21$ & Minimum/normal \\
\hline $21-25$ & Mild \\
\hline $26-33$ & Moderate \\
\hline$\geq 34$ & Severe \\
\hline
\end{tabular}




\subsection{Choosing Models and Its Solution}

The depression issues usually represent with particular psychology measuring scale, such as Beck Depression Inventory. Beck Depression Inventory (BDI) is a measuring scale that aims to determine the severity of depression[8]. The BDI works in many aspects such as adolescents[9], patients[10], pregnancy[11] and others. BDI has 21 criteria, shown in Table 1[12]. Each item consists of 4 level statements that rated on intensity on a scale of 0-3 [13]. The results of BDI, obtained by multiplying each criterion with the client questionnaire answers. The maximum score of BDI is 63. BDI results represent levels of depression.

The BDI manual has determined one weight for all criteria, so it does not support the decision of a group of psychologists. BDI will be combined with several methods to overcome this.

Table 2. Criterion of BDI

\begin{tabular}{cl}
\hline Index & \multicolumn{1}{c}{ Criterion } \\
\hline K1 & Sadness \\
\hline K2 & Pessimism \\
\hline K3 & Feel failed \\
\hline K4 & Not satisfied \\
\hline K5 & Feel guilty \\
\hline K6 & Feel punished \\
\hline K7 & Self-hate \\
\hline K8 & Blame your self \\
\hline K10 & Suicidal tendency \\
\hline K11 & Crying \\
\hline K12 & Irritability \\
\hline K13 & Social Withdrawal \\
\hline K14 & Indecision \\
\hline K15 & Feel ugly \\
\hline K16 & Decrease activity \\
\hline K17 & Sleep disorder \\
\hline K18 & Fatigue \\
\hline K19 & Changing in appetite \\
\hline K20 & Loss in body weight \\
\hline K21 & Somatic preoccupation \\
\hline & Loss of sexual interest \\
\hline
\end{tabular}

The proposed new model is a group decision support model, which combines BDI with Analytical Hierarchy Process (AHP) and Geometric Mean.

The depression issues is a problem with multiple criteria. It is suitable to Multiple Criteria Decision Making (MCDM) model. The one of MCDM solution is AHP. This AHP comparing each criterion with create matrix of pairwise comparison judgement. The method used to determine weight of each BDI criterion based on psychologist preference. AHP has ability to test the consistency of preferences, to decrease subjectivity's issues. The procedure following some steps, they are [14]:

1) Define the objectives and problem decomposition 
2) Determine the priority element. Comparative judgment on the pairwise comparison matrix using the nominal ratio scale of 1 to 9 among decision elements and form comparison matrices.

3) Normalize the pairwise comparison matrices using formula (1) and calculate the weight criterion vector (Wi) using formula (2)

$$
\begin{aligned}
A^{\prime} & =\frac{a_{i j}}{\sum_{i=1}^{n} \sum_{j=1}^{m} a_{i j}} \\
\mathrm{w}_{\mathrm{i}} & =\frac{\sum_{i=1}^{n} \sum_{j=1}^{m} a_{i j}}{N}
\end{aligned}
$$

4) Test of consistency, consist of 5 steps as follows:

a) Multiplying the comparison matrix by the weight column to get the weighted sum vector.

b) Calculate the consistency vector. The weighted sum vector divided by the weight vector,

c) Compute the lamda ( $\lambda$ ) max. The consistency vector divided by the matrix size

d) Compute the consistency index through formula (3)

$$
C I=\frac{\lambda \max -n}{n-1}
$$

e) Calculate the consistency ratio. Consistency index divided by Random Index (RI). The RI use the value proposes by Alonso and Lamata [15]. If the value of the consistency ratio is greater than 0.1 , it is inconsistent judgments. We need to revise the subjective judgment.

Geometric mean chosen to get one value of preference of group psychologist. The aim of this technique is to avoid the gap preference among psychologist. The implementation of geometric mean in AHP, will increase consensus rate [15, 16]. The formula of Geometric Mean (GM) shown in (4).

$$
G M=\sqrt[n]{a_{1} \bullet a_{2} \bullet a_{3} \cdots a_{n}}
$$

\subsection{Evaluation Models}

The last phase is evaluating models with comparing the depression prognosis between the usual approach (only BDI) with the new one, BDI-AHP-GM hybrid.

\section{Result and discussion}

The steps of problem solving shown in Figure 2. 


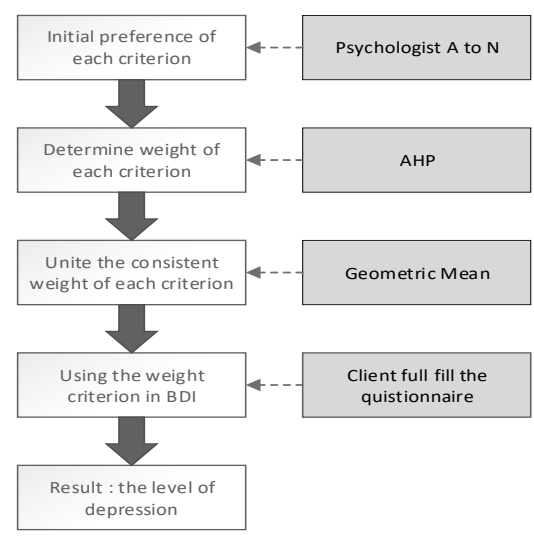

Fig 2. Step of Problem Solving

\section{1 Decision Model}

Figure 2. This section describe the result of implementation models using the sample data. According to AHP steps, each psychologist gives their preference values than the values will be comparing as pairwise in the matrix (check step 3 of AHP). The pairwise comparison matrix will be normalized (check step 4 of AHP). The matrix normalization given in Table VI. The result of weighted vector for each criterion, shown in Table III. This result have been proven to be consistent through consistency test, with consistency ratio of 0.053 .

Table 3. The Criteria Weighted Consistency Psychologist

\begin{tabular}{ccc}
\hline Index & $\begin{array}{c}\text { Weighted Criterion } \\
\text { Psychologist A }\end{array}$ & $\begin{array}{c}\text { Weighted Criterion } \\
\text { Psychologist } \mathbf{~}\end{array}$ \\
\hline K1 & 0.053288 & 0.054103898 \\
\hline K2 & 0.025456 & 0.027385339 \\
\hline K3 & 0.050367 & 0.051185965 \\
\hline K4 & 0.023978 & 0.025826522 \\
\hline K5 & 0.047624 & 0.048436639 \\
\hline K6 & 0.04504 & 0.045837486 \\
\hline K7 & 0.09528 & 0.096019928 \\
\hline K8 & 0.089247 & 0.089943875 \\
\hline K1 & 0.175145 & 0.175722307 \\
\hline K11 & 0.022545 & 0.024317127 \\
\hline K12 & 0.021153 & 0.022854116 \\
\hline K13 & 0.083894 & 0.084557486 \\
\hline K14 & 0.042015 & 0.021434723 \\
\hline K15 & 0.079083 & 0.079719802 \\
\hline K16 & 0.019801 & 0.020056421 \\
\hline K17 & 0.013385 & 0.013507117 \\
\hline K19 & 0.012413 & 0.012521801 \\
\hline K20 & 0.010527 & 0.010610304 \\
\hline K21 & 0.040259 & 0.043372941 \\
\hline & 0.038038 & 0.04102974 \\
\hline
\end{tabular}


Furthermore, Geometric Mean calculations are performed so that the consensus value of the criteria is obtained, can seen in Table 4.

Table 4. The Consensus Value Of Weighted Criteria

\begin{tabular}{cc}
\hline Index & The Consensus Value of Weighted Criteria \\
\hline K1 & 0.053694395 \\
\hline K2 & 0.026403232 \\
\hline K3 & 0.050774821 \\
\hline K4 & 0.024885203 \\
\hline K6 & 0.048028488 \\
\hline K7 & 0.045437146 \\
\hline K8 & 0.095649088 \\
\hline K9 & 0.08959454 \\
\hline K10 & 0.175433659 \\
\hline K11 & 0.023414072 \\
\hline K12 & 0.021987019 \\
\hline K13 14 & 0.084225045 \\
\hline K15 & 0.030009794 \\
\hline K16 & 0.079400985 \\
\hline K17 & 0.019928108 \\
\hline K18 & 0.01344608 \\
\hline K19 & 0.012467488 \\
\hline K20 & 0.011508604 \\
\hline K21 & 0.010568649 \\
\hline & 0.041787185 \\
\hline
\end{tabular}

The values shown in Table 4 are used in BDI calculations. The client questionnaire answer multiplied by that values. Normalization process is carried out against the total value of the multiplication of results. The final score is generated are 30.052 , this is equivalent to the middle depression level.

\subsection{Model Testing Result}

This test is to see the feasibility of the new model (BDI combine to AHP \& Geometric Mean) offered. The test begins with filling out the questionnaire then the results will be calculated using the old method (just BDI) and the newly proposed method.

The result test shown in Table V. Based on that, can be seen that 7 out of 10 trials show the same level of depression, even though the total score is slightly different (Fig.3).

Table 5. Comparison of Depression Levels Status

\begin{tabular}{lll}
\hline BDI & BDI-AHP-GM \\
\hline
\end{tabular}




\begin{tabular}{|c|c|c|}
\hline Client I & Mild (10) & Mild (9.24) \\
\hline \multicolumn{3}{|l|}{ Client II } \\
\hline \multicolumn{3}{|l|}{ Client III } \\
\hline \multicolumn{3}{|l|}{ Client IV } \\
\hline \multicolumn{3}{|l|}{ Client V } \\
\hline \multicolumn{3}{|l|}{ Client VI } \\
\hline \multicolumn{3}{|l|}{ Client VII } \\
\hline \multicolumn{3}{|l|}{ Client VIII } \\
\hline \multicolumn{3}{|l|}{ Client IX } \\
\hline \multicolumn{3}{|l|}{ Client X } \\
\hline $\begin{array}{l}70 \\
60 \\
50 \\
40 \\
30 \\
20 \\
10 \\
-\end{array}$ & $-\mathrm{BDI}$ & I-AHP-GM \\
\hline
\end{tabular}

Fig 3. Comparison of Depression Level Scores

The model testing also carried out in the presence of expert from PUSKAGA UII. Expert state that this model quite valid.

\section{Conclution}

The conclusion made is that a group decision support model has been produced to determine the level of depression among married couples. This new model combines BDI with AHP and Geometric Mean. The model provides an opportunity for the group of a psychologist to give their preferences with the minimal element of subjectivity. The proposed model is quite valid. 
The suggestion for this work, should be field testing before applied to Group Decision Support System.

\section{Acknowledgment}

This paper is part of a research that has full funding support from the Ministry of Research, Technology and Higher Education through the Higher Education Leading Research Grants entering the second year. The study also received support from PUSKAGA UII in the form of data provision, knowledge reference, implementation, and testing.

\section{References}

[1] WHO, "Mental Disorder", posted on 9April 2018, accessed on 26 September 2018 from http://www.who.int/news-room/fact-sheets/detail/mental-disorders,

[2] Health Research And Development Agency Of The Ministry Of Health RI, "Riset Kesehatan Dasar 2013", accessed on 26 September 2018, from http://www.depkes.go.id/resources/download/general/Hasil\%20Riskesdas\%202013

[3] K. Iyer, Z.A. Khan, “Depression : A review, Research Journal of Recent Sciences”, Vol 1(4), April 2012, pp.7978.

[4] E.R. Mitchell, C.R.Cronkite, \& H.R.Moos, "Stress, coping, and depression among married couples". Journal of Abnormal Psychology, 92(4),1983, pp. 433-448.

[5] A.M.Whisman, L.M.Bruce, "Marital dissatisfaction and incidence of major depressive episode in a community sample". Journal of Abnormal Psychology, 108(4), 1999. pp.674-678.

[6] M. B. Gastaud, C. F. Feilb, M. G. Merg and M. L. Tiellet Nunes, "Psychological Assessment as a Protective Factor against Treatment Dropout in Psychoanalytic Child Psychotherapy of Children: Empirical Data," Psychology/Psicologia Refl exão e Crítica, 27(3), 2014, pp.498-503.

[7] R. A. Steer, A. T. Beck, and B. Garisson, "Chapter 13 Application of The Beck Depression Inventory", Sartorius et al. (eds.), Assessment of Depression @ Springer-Verlag Berlin Heidelberg, 1986. pp. 123-124

[8] H, Kim, C.A.M Mazenga, I. D. Akash, S. Ahmed, P.N Kazembe, X.Yu, C.Nguyen, and C.Sharp, "Prevalence of depression and validation of the Beck Depression Inventory-II and the Children's Depression Inventory-Short among HIV-positive adolescents in Malawi”, Journal of the International AIDS Society, 17:18965, 2014, pp. 18.

[9] P. Daniel Pietrzaka, Aldona Pietrzakb,, Dorota Krasowskab, Marta Makara-Studzińskac, Agata Madejc, Maja Baranowskad, Andrzej Borzęcki, Depressiveness, measured with Beck Depression Inventory, in patients with psoriasis, Journal of Affective Disorders 209. 2017. pp. 229-234.

[10] H.Koleva, S.Stuart, M.W.Ohara, J.B. Reif, "Risk factors for depressive symptoms during pregnancy", Archives of Women's Mental Health, April 2011, Volume 14, Issue 2, pp 88-105.

[11] P. Richter, J. Werner, A. Heerlein, A. Kraus and H. Sauer, "On the validity ofthe Beck Depression Inventory," PaperPsychopathology, vol. Psychopathology 31, 1998, pp. 160-168

[12] Z.E.G.'a-Batista, K.G Peña, A.C.Vindel, S.X.H.Martines, L.A. Medrano, "Validity and reliability of the Beck Depression Inventory (BDI-II) in general and hospital population of Dominican Republic, PLoS ONE 13 (6): e0199750, June 2018, pp.1-12.

[13] Beck AT, Steer RA and Brown GK (1996) "Manual for the Beck Depression Inventory-II". San Antonio, TX: Psychological Corporation

[14] L.T. Saaty,. "A Scaling Method for Priorities in Hierarchical Structures”, J Math Psychol 15(3), 1977, pp. 234281.

[15] D.Yucheng, Z.Guiqing, H. Wei-Chiang, X. Yinfeng, "Consensus Models for AHP Group Decision Making Under Row Geometric Mean Prioritization Method”, Decision Support Systems, Volume 49, Issue 3, pp.281289, June 2010. 